University of Nebraska - Lincoln

DigitalCommons@University of Nebraska - Lincoln

Faculty Publications: Department of Entomology

Entomology, Department of

2014

\title{
Global spread of wheat curl mite by its most polyphagous and pestiferous lineages
}

\author{
A. Skoracka \\ Institute of Environmental Biology, anna.skoracka@amu.edu.pl \\ B. Rector \\ USDA-ARS, Great Basin Rangelands Research Unit \\ L. Kuczyński \\ Institute of Environmental Biology \\ W. Szydło \\ Institute of Biology \\ G. Hein \\ University of Nebraska-Lincoln, ghein1@unl.edu
}

See next page for additional authors

Follow this and additional works at: https://digitalcommons.unl.edu/entomologyfacpub

Part of the Entomology Commons

Skoracka, A.; Rector, B.; Kuczyński, L.; Szydło, W.; Hein, G.; and French, R., "Global spread of wheat curl mite by its most polyphagous and pestiferous lineages" (2014). Faculty Publications: Department of Entomology. 360.

https://digitalcommons.unl.edu/entomologyfacpub/360

This Article is brought to you for free and open access by the Entomology, Department of at DigitalCommons@University of Nebraska - Lincoln. It has been accepted for inclusion in Faculty Publications: Department of Entomology by an authorized administrator of DigitalCommons@University of Nebraska - Lincoln. 


\section{Authors}

A. Skoracka, B. Rector, L. Kuczyński, W. Szydło, G. Hein, and R. French 


\title{
Global spread of wheat curl mite by its most polyphagous and pestiferous lineages
}

\author{
A. Skoracka ${ }^{1}$, B. Rector ${ }^{2}$, L. Kuczyński ${ }^{3}$, W. Szydło ${ }^{1}$, G. Hein ${ }^{4}$ \& R. French ${ }^{5}$ \\ 1 Department of Animal Taxonomy and Ecology, Institute of Environmental Biology, Faculty of Biology, Adam Mickiewicz University, Poznań, Poland \\ 2 USDA-ARS, Great Basin Rangelands Research Unit, Reno, NV, USA \\ 3 Department of Avian Biology and Ecology, Institute of Environmental Biology, Faculty of Biology, Adam Mickiewicz University, Poznań, Poland \\ 4 Department of Entomology, University of Nebraska-Lincoln, Lincoln, NE, USA \\ 5 United States Department of Agriculture-Agricultural Research Service and Department of Plant Pathology, University of Nebraska-Lincoln, Lincoln, NE, \\ USA
}

\section{Keywords}

Aceria tosichella; invasiveness; cryptic species; Eriophyidae; host range; molecular taxonomy.

\section{Correspondence \\ A. Skoracka, Department of Animal Taxonomy and Ecology, Institute of Environmental Biology, Faculty of Biology, Adam Mickiewicz University, Umultowska 89, 61-614 Poznań, Poland. \\ Email: anna.skoracka@amu.edu.pl}

Received: 10 August 2013; revised version accepted: 25 March 2014.

doi:10.1111/aab.12130

\begin{abstract}
The wheat curl mite (WCM), Aceria tosichella, is an important pest of wheat and other cereal crops that transmits wheat streak mosaic virus and several other plant viruses. Wheat curl mite has long been considered a single polyphagous species, but recent studies in Poland revealed a complex of genetically distinct lineages with divergent host-acceptance traits, ranging from highly polyphagous to host-specific. This diversity of WCM genotypes and host-acceptance phenotypes in Europe, the presumed native range of WCM, raises questions about the lineage identities of invasive WCM populations on other continents and their relationships to European lineages. The goals of this study were to examine the global presence of WCM and determine the relatedness of lineages established in different continents, on the basis of phylogenetic analyses of mitochondrial and nuclear DNA sequence data. Host-range bioassays of a highly polyphagous WCM lineage were performed to supplement existing data on this lineage's ability to colonise graminaceous and non-graminaceous hosts. Invasive WCM populations in North and South America and Australia assorted with the only three known polyphagous and pestiferous WCM lineages ('MT-1', 'MT-7' and 'MT-8') from a total of eight currently described lineages. These results show that the most polyphagous lineages were more successful colonisers and reflect a need for extensive surveys for WCM on both crops and wild grass species in invaded continents. The most invasive lineage ('MT-1') was shown to successfully colonise all 10 plant species tested in three families and has spread to North and South America and Australia from its presumed origins in Eurasia.
\end{abstract}

\section{Introduction}

Increased intercontinental tourism and trade favour the worldwide dissemination of taxa that are otherwise constrained by geographical barriers, resulting in environmental, ecological and economic impacts on biological communities and ecosystems (e.g. Pimentel et al., 2000). Invasive species may adversely alter communities of native species, thereby modifying ecosystem functions and creating major problems for agriculture through the transmission of diseases and pathogens, as well as direct damage to crops (e.g. Honek \& Martinkova, 2011; Benheim et al., 2012; Mazzi \& Dorn, 2012; Juárez-Escario et al., 2013; Wang et al., 2013).

Eriophyoid mites are phytophagous arthropods that have high potential as invasive organisms because their minute size makes them difficult to detect. As such, they can be easily distributed through trade or other movement of their host plants. Eriophyoidea include many important pests of agriculture and forestry worldwide, responsible 
for yield losses via direct damage or disease transmission (Oldfield \& Proeseler, 1996; Duso et al., 2010). Eriophyoid species have been reported as invasive and represent quarantine concerns in numerous countries (Navia et al., 2010). The implementation of appropriate control and risk mitigation strategies for eriophyoid mites can be hampered by the difficulty of taxonomic identification due to their microscopic size and their morphological simplicity and ambiguity under current descriptions (Lindquist \& Amrine, 1996). The existence of cryptic, often host-associated, genetic lineages can also confound such efforts (Magalhães et al., 2007; Skoracka et al., 2012). Recent molecular genetic studies have detected cryptic species complexes in eriophyoid mites (Carew et al., 2009; Skoracka \& Dabert, 2010; Miller et al., 2013; Skoracka et al., 2013). Elucidation of such ill-defined taxonomic relationships for agriculturally important Eriophyoidea is critical to the development of tools such as efficient diagnostic keys that integrate morphological, behavioural and molecular characters to facilitate targeted control of pestiferous lineages.

The majority of eriophyoid species are known to be highly host-specific (Skoracka et al., 2010), whereas the wheat curl mite (WCM), Aceria tosichella (Keifer) (Acari: Prostigmata: Eriophyoidea), has been commonly characterised as a single, highly polyphagous species with $>80$ species of Poaceae recorded as hosts (Navia et al., 2013). The WCM is an important pest of wheat and other cereal crops (e.g. barley, corn, oat, pearl millet, rye, sorghum), with direct yield losses to wheat reaching 30\% (Styer \& Nault, 1996; Harvey et al., 2002; Navia et al., 2010). The mite is also known to transmit several plant viruses, including wheat streak mosaic virus (WSMV), a major pathogen of wheat in North and South America, Europe, the Middle East, Oceania and Asia, that can cause complete crop loss in infested fields (Navia et al., 2013). Other plant diseases transmitted by WCM include wheat spot mosaic virus (Jeppson et al., 1975), brome streak mosaic virus (Stephan et al., 2008), High Plains virus (Seifers et al., 1997) and triticum mosaic virus (Seifers et al., 2009). The latter three can occur in mixed infections with WSMV (Byamukama et al., 2013). Wheat curl mite and its associated viruses have been recorded as major yield reduction factors of wheat crops in North America for about 60 years and in recent decades the mite has emerged as a serious threat to cereal production in Australia and South America (Navia et al., 2013).

Recent phylogenetic analyses of DNA sequence diversity have revealed the existence of different genotypes or perhaps cryptic species within A. tosichella (sensu lato). Carew et al. (2009) identified two distinct WCM lineages present in several invasive Australian populations collected from wheat and other grass hosts.
These two lineages were shown to have overlapping geographical distributions, while only one lineage is implicated in WSMV transmission (Schiffer et al., 2009). Hein et al. (2012) found two genetically distinct WCM populations in North America that corresponded to the Australian mite populations. Moreover, a comprehensive phylogenetic analysis of WCM from different host plants and on four continents revealed several additional unique WCM lineages with species level differences in sequence diversity (Skoracka et al., 2012; Miller et al., 2013). A study of WCM genetic and host-range variability in western Poland identified seven genetic lineages (designated 'MT-1' through 'MT-7') with variable host ranges, including divergent host-acceptance and specificity traits. Genetic variation for host-acceptance may act as a pre-zygotic reproductive barrier between these lineages (e.g. Schluter, 2001; Nosil, 2007). Lineages ranged from highly polyphagous and pestiferous to more host-specific, including several WCM lineages, collected from wild grass species, that were not able to colonise wheat (Skoracka et al., 2013). Of the seven lineages collected in Poland, only one (MT-1) showed the highly polyphagous habit that is commonly associated with WCM, attacking nine of ten test species in host-acceptance experiments, including wild and cultivated grasses as well as cultivated Allioidae and Liliaceae but excluding maize (Skoracka et al., 2013). Host-range bioassays on the polyphagous MT-1 lineage were performed in this study to supplement existing data on its ability to colonise maize, garlic, onion and tulip. The great diversity of genotypes and host-acceptance phenotypes found in Poland raises questions about the lineage identities of invasive WCM populations on other continents compared to European lineages. To date, no comprehensive study has attempted to unequivocally delineate the native range of WCM although the variety of lineages found on both domesticated and wild grass species in Europe (Skoracka et al., 2012; Miller et al., 2013) suggests that it overlaps with the southwest Asian ('fertile crescent') origins of cereal species.

The goals of this study were to examine the global presence of WCM and determine whether the lineages that have become established in Australia and North and South America are related to lineages that have been described in the putative native range of WCM in Europe. We hypothesise that spread of WCM is associated with the global trade in agricultural plants and that lineages found in recent intercontinental invasions of WCM would have arisen from the most pestiferous and polyphagous European lineages. In short, lineages most able to reproduce on crop species would be most likely to spread to new continents. The existence of numerous genetically distinct WCM lineages with divergent 
host-ranges, in addition to the worldwide spread of WCM, provides a system through which invasion potential could be examined post hoc within a single species complex on the basis of host-range and human association.

\section{Materials and methods}

Experiments testing the host colonisation ability of MT-1 lineage

The stock colony

Specimens of WCM lineage MT-1 [detected in previous study: Skoracka et al. (2013), (GenBank: JF920077)] originating from the stock colony maintained on bread wheat Triticum aestivum L. for several months in the laboratory of Department of Animal Taxonomy and Ecology, Faculty of Biology, Adam Mickiewicz University were used in these experiments. Details for preparing the stock colony are described in Skoracka et al. (2013).

\section{Experimental plants}

Three cereal species: bread wheat var. Tonacja (as control), triticale ( $\times$ Triticosecale Wittm. ex A. Camus) var. Hortenso, maize (Zea mays L.) var. Mas22.R; two economically important Amaryllidaceae species: bulb onion (Allium cepa L.) var. Red Baron and garlic (Allium sativum L.) var. Harnaś; and one ornamental Liliaceae species: Didier's tulip (Tulipa gesneriana L.), were used as experimental plants. Cereals were grown from commercially available seeds in pots and kept in cages. Bulbs of garlic, onion and tulip were cleaned and checked for the presence of any arthropods or disease symptoms before being used.

\section{Mite colonisation test}

Previous experiments (Skoracka et al., 2013) showed that females of the MT-1 lineage successfully colonised wheat, barley and triticale when transferred directly from wheat in small numbers; however, they did not attain high population growth on maize. Given that a population of WCM was collected from the field on maize subsequent to that study (see Table 1) and given that MT-1 was the most polyphagous known WCM lineage, a new colonisation test was performed to determine if MT-1 could move from heavily infested wheat plants to clean maize plants. Cut shoots of wheat plants infested with MT-1 mites from stock colonies were placed in contact with clean shoots of laboratory-grown wheat, triticale or maize plants and were removed after $24 \mathrm{~h}$. The densities of MT-1 populations in the stock colony were estimated and the number of mites per shoot ranged from 100 to
$210($ mean $=170)$. Experimental plants were inspected after 14 and 29 days. Experimental plants were not destroyed during the first inspection, that is 14 days post-infestation, therefore exact counts of mites were not made at this time although estimation of population increase on the test plants was made in order to check whether mites had colonised plants and whether they were reproducing. During the second inspection, 29 days post-infestation, plants were destroyed and all mites were counted. Some mites were preserved in ATL buffer (Qiagen GmbH, Hilden, Germany; a tissue lysis buffer for use in purification of nucleic acids) for subsequent genotyping. Additional test plants with mites were kept until 45 days post-infestation, however, quantitative data were not possible to obtain after that time due to very high population densities. Thus, for these last observations the only information gathered was whether the population was still thriving after 45 days and mites were collected in ATL buffer for genotyping. For each plant species tested, four trials (repetitions) were carried out. Eight plants per treatment per trial were used. Experimental plant species with mites were maintained separately in rearing cages under stable conditions $\left(20-21^{\circ} \mathrm{C}, 50-60 \%\right.$ humidity).

\section{Population growth on Amaryllidaceae and Liliaceae}

Previous experiments (Skoracka et al., 2013) demonstrated that females of the MT-1 lineage successfully colonised bulbs within 14 days of infestation when transferred directly to garlic, onion and tulip. However, it was not known if the grass associated MT-1 lineage would continue its development and reproduction after a longer time on plants belonging to families other than Poaceae. To answer this question, an experiment with a longer duration was conducted. MT-1 females from stock colonies were transferred to clean potted wheat plants (control) and clean bulbs of Amaryllidaceae (garlic and onion) and Liliaceae (tulip). Eriophyoid mites reproduce by arrhenotoky whereby young females pick up spermatophores dropped by males (Michalska et al., 2010). Thus, MT-1 females transferred from an active colony to new plants in these studies were likely to have been fertilised; eggs of unfertilised females can still develop parthenogenetically and produce all male offspring. For each test-plant species, five trials (repetitions) were carried out. A trial was defined as a single plant or bulb with 15 females transferred to them. Thus, for each test-plant species 75 females were transferred ( 300 females in total). Ten minutes after mite transfer, plants and bulbs were checked to count the number of females that had successfully settled on them. This number was defined as the number of females engaged in the experiment for a given trial (hereafter 'experimental females'). Females that appeared 
Table 1 Characteristics of the WCM sequences used in this study: country, host plant taxa, GPS coordinates of the collection sites, GenBank accession numbers (sequences downloaded from GenBank denoted by *), sequence numbers that correspond to those in Figs 3-5, references where the sequences were published ${ }^{\mathrm{a}}$

\begin{tabular}{|c|c|c|c|c|c|c|}
\hline \multirow[b]{2}{*}{ Country } & \multirow[b]{2}{*}{ Host Plant Taxon } & \multirow[b]{2}{*}{ Latitude, Longitude } & \multicolumn{2}{|c|}{ Accession Numbers } & \multirow[b]{2}{*}{ Seq. no. } & \multirow[b]{2}{*}{ Ref } \\
\hline & & & $\mathrm{COI}$ & ITS & & \\
\hline Texas, USA & Bread wheat & $\mathrm{n} / \mathrm{a}$ & JX102049 & $J \times 087362^{*}$ & 20 & ts \\
\hline \multirow[t]{2}{*}{ Nebraska, USA } & $\begin{array}{l}\text { Bread wheat, Triticum } \\
\text { aestivum L. }\end{array}$ & $\mathrm{n} / \mathrm{a}$ & $J \times 102055$ & JX087356* & 9 & ts \\
\hline & Bread wheat & $\mathrm{n} / \mathrm{a}$ & & JX087359* & 36 & 1 \\
\hline Argentina & Bread wheat & $36^{\circ} 46^{\prime} 59^{\prime \prime} \mathrm{S}, 59^{\circ} 51^{\prime} 12^{\prime \prime} \mathrm{W}$ & JF920073* & $\begin{array}{l}\text { JF960142* } \\
\text { JF960143* }\end{array}$ & 7. & 2 \\
\hline Brazil & Bread wheat & $28^{\circ} 14^{\prime} 60^{\prime \prime} \mathrm{S}, 52^{\circ} 24^{\prime} 00^{\prime \prime} \mathrm{W}$ & JF920072* & $\begin{array}{l}\text { JF960139*, } \\
\text { JF960140* }\end{array}$ & $6 \mathrm{~A}$ & 2 \\
\hline \multirow[t]{6}{*}{ Australia } & $\begin{array}{c}\text { Rescuegrass, Bromus } \\
\text { catharticus Vahl }\end{array}$ & $33^{\circ} 07^{\prime} 16^{\prime \prime} \mathrm{S}, 148^{\circ} 58^{\prime} 32^{\prime \prime} \mathrm{E}$ & JF920092* & & 4 & 2 \\
\hline & $\begin{array}{l}\text { Wall barley, Hordeum } \\
\text { murinum L. }\end{array}$ & $33^{\circ} 12^{\prime} 15^{\prime \prime} \mathrm{S}, 148^{\circ} 50^{\prime} 32^{\prime \prime} \mathrm{E}$ & JF920082* & JF960160* & 12 & 2 \\
\hline & Bread wheat & $33^{\circ} 14^{\prime} 41^{\prime \prime} \mathrm{S}, 148^{\circ} 58^{\prime} 54^{\prime \prime} \mathrm{E}$ & JF920080* & & 13 & 2 \\
\hline & & $33^{\circ} 17^{\prime} 47^{\prime \prime} \mathrm{S}, 148^{\circ} 54^{\prime} 57^{\prime \prime} \mathrm{E}$ & JF920078* & JF960157* & 15 & 2 \\
\hline & & $\mathrm{n} / \mathrm{a}$ & & EU734726* & 29 & 3 \\
\hline & & $\mathrm{n} / \mathrm{a}$ & & EU734729* & 30 & 3 \\
\hline \multirow[t]{22}{*}{ Poland } & $\begin{array}{l}\text { Quackgrass, Elymus } \\
\text { repens (L.) Gould }\end{array}$ & $52^{\circ} 27^{\prime} 55^{\prime \prime} \mathrm{N}, 16^{\circ} 55^{\prime} 55^{\prime \prime} \mathrm{E}$ & $\begin{array}{l}\text { JQ248913*, JQ248919*, } \\
\text { JQ248915*, JQ248914*, } \\
\text { JQ248916*, JQ248917*, } \\
\text { JQ248918* }\end{array}$ & & $\begin{array}{c}1,1 \mathrm{~A}, 1 \mathrm{~B}, 1 \mathrm{C} \\
1 \mathrm{D}, 1 \mathrm{E}, 1 \mathrm{~F}\end{array}$ & 4 \\
\hline & & $50^{\circ} 07^{\prime} 29^{\prime \prime} \mathrm{N}, 16^{\circ} 42^{\prime} 47^{\prime \prime} \mathrm{E}$ & KF975391 & & 21 & ts \\
\hline & & $50^{\circ} 32^{\prime} 02^{\prime \prime} \mathrm{N}, 16^{\circ} 27^{\prime} 43^{\prime \prime} \mathrm{E}$ & KF975392 & & 22 & ts \\
\hline & & $51^{\circ} 11^{\prime} 02^{\prime \prime} \mathrm{N}, 15^{\circ} 13^{\prime} 56^{\prime \prime} \mathrm{E}$ & KF975393 & & 23 & ts \\
\hline & & $50^{\circ} 56^{\prime} 34^{\prime \prime} \mathrm{N}, 15^{\circ} 30^{\prime} 13^{\prime \prime} \mathrm{E}$ & KF975394 & & 24 & ts \\
\hline & $\begin{array}{l}\text { Smooth brome, Bromus } \\
\text { inermis Leyss }\end{array}$ & $52^{\circ} 28^{\prime} 03^{\prime \prime} \mathrm{N}, 16^{\circ} 54^{\prime} 31^{\prime \prime} \mathrm{E}$ & JQ248920*, JQ248922* & & 2 , & 4 \\
\hline & & $52^{\circ} 24^{\prime} 00^{\prime \prime} \mathrm{N}, 16^{\circ} 37^{\prime} 32^{\prime \prime} \mathrm{E}$ & KC430098 & & 19 & ts \\
\hline & & $50^{\circ} 44^{\prime} 03^{\prime \prime} \mathrm{N}, 16^{\circ} 36^{\prime} 35^{\prime \prime} \mathrm{E}$ & KF975396 & & 25 & ts \\
\hline & $\begin{array}{l}\text { Tall oat-grass, } \\
\text { Arrhenatherum elatius } \\
\text { (L.) P. Beauv. ex J. \& C. }\end{array}$ & $52^{\circ} 27^{\prime} 59^{\prime \prime} \mathrm{N}, 16^{\circ} 56^{\prime} 03^{\prime \prime} \mathrm{E}$ & $\begin{array}{l}\text { JQ248923*, JQ248924*, } \\
\text { JQ248925* }\end{array}$ & & $\begin{array}{l}3 \mathrm{~A} \\
3 \mathrm{~B}\end{array}$ & 4 \\
\hline & Presl & $52^{\circ} 29^{\prime} 02^{\prime \prime} \mathrm{N}, 16^{\circ} 40^{\prime} 50^{\prime \prime} \mathrm{E}$ & KF975395 & & 26 & ts \\
\hline & & $52^{\circ} 02^{\prime} 23^{\prime \prime} \mathrm{N}, 16^{\circ} 46^{\prime} 09^{\prime \prime} \mathrm{E}$ & KF975397 & & 27 & ts \\
\hline & & $52^{\circ} 27^{\prime} 01^{\prime \prime} \mathrm{N}, 17^{\circ} 14^{\prime} 53^{\prime \prime} \mathrm{E}$ & KF975398 & & 28 & ts \\
\hline & $\begin{array}{c}\text { Triticale, } \times \text { Triticosecale } \\
\text { Wittm. ex A. Camus }\end{array}$ & $51^{\circ} 50^{\prime} 25^{\prime \prime} \mathrm{N}, 17^{\circ} 09^{\prime} 05^{\prime \prime} \mathrm{E}$ & KC422635 & & 17 & ts \\
\hline & Maize, Zea mays L. & $52^{\circ} 27^{\prime} 27^{\prime \prime} \mathrm{N}, 17^{\circ} 13^{\prime} 18^{\prime \prime} \mathrm{E}$ & KC422636 & & 18 & ts \\
\hline & Bread wheat & $50^{\circ} 34^{\prime} 28^{\prime \prime} \mathrm{N}, 19^{\circ} 29^{\prime} 18^{\prime \prime} \mathrm{E}$ & JF920077* & JF960148* & 5 & 2 \\
\hline & & $51^{\circ} 11^{\prime} 02^{\prime \prime} \mathrm{N}, 15^{\circ} 13^{\prime} 55^{\prime \prime} \mathrm{E}$ & KC422632 & & 14 & ts \\
\hline & & $51^{\circ} 11^{\prime} 02^{\prime \prime} \mathrm{N}, 15^{\circ} 13^{\prime} 56^{\prime \prime} \mathrm{E}$ & $\begin{array}{l}\text { KJ000667, KJ000668, } \\
\text { KJ000669 }\end{array}$ & & $35,35 \mathrm{~A}, 35 \mathrm{~B}$ & ts \\
\hline & Wall barley & $52^{\circ} 27^{\prime} 46^{\prime \prime} \mathrm{N}, 16^{\circ} 55^{\prime} 29^{\prime \prime} \mathrm{E}$ & $\begin{array}{l}\text { JQ248926*, JQ248928*, } \\
\text { JQ248927* }\end{array}$ & & $11,11 \mathrm{~A}, 11 \mathrm{~B}$ & 4 \\
\hline & & $52^{\circ} 22^{\prime} 54^{\prime \prime} \mathrm{N}, 16^{\circ} 56^{\prime} 06^{\prime \prime} \mathrm{E}$ & JF960152* & & 34 & 2 \\
\hline & & $52^{\circ} 27^{\prime} 37^{\prime \prime} \mathrm{N}, 16^{\circ} 55^{\prime} 25^{\prime \prime} \mathrm{E}$ & KF975399 & & 31 & ts \\
\hline & & $52^{\circ} 23^{\prime} 53^{\prime \prime} \mathrm{N}, 16^{\circ} 56^{\prime} 24^{\prime \prime} \mathrm{E}$ & KF975400 & & 32 & ts \\
\hline & & $52^{\circ} 22^{\prime} 53^{\prime \prime} \mathrm{N}, 16^{\circ} 56^{\prime} 07^{\prime \prime} \mathrm{E}$ & KF975401 & & 33 & ts \\
\hline \multirow[t]{3}{*}{ Turkey } & Bread wheat & $40^{\circ} 32^{\prime} 04^{\prime \prime} \mathrm{N}, 43^{\circ} 06^{\prime} 33^{\prime \prime} \mathrm{E}$ & KC412865 & & 8 & ts \\
\hline & & $39^{\circ} 01^{\prime} 41^{\prime \prime} \mathrm{N}, 43^{\circ} 21^{\prime} 42^{\prime \prime} \mathrm{E}$ & KC412861 & KJ000671 & 16 & ts \\
\hline & Wall barley & $38^{\circ} 00^{\prime} 28^{\prime \prime} \mathrm{N}, 43^{\circ} 03^{\prime} 39^{\prime \prime} \mathrm{E}$ & KC412857 & KJ000670 & 10 & ts \\
\hline
\end{tabular}

COI, cytochrome c oxidase subunit I; GPS, Global Positioning Satellite; ITS, internal transcribed spacer; WCM, wheat curl mite.

${ }^{a}$ References for GenBank sequences: 1, Hein et al. (2012); 2, Skoracka et al. (2012); 3, Carew et al. (2009); 4, Skoracka et al. (2013); ts, this study. 
dead or injured during the post-transfer inspection were removed from the plants and bulbs (ca. 3\%). Experimental plants and bulbs with transferred females were kept in cages (as described above) under laboratory conditions $\left(20-21^{\circ} \mathrm{C}, 50-60 \%\right.$ humidity) for 28 days post-infestation. Plants and bulbs were then inspected and the number of mites was counted using a stereomicroscope. Mites were collected from test plants and preserved for molecular analysis (see below). After this inspection, bulbs were kept under laboratory conditions for 85 days post-infestation (tulip) or 150 days post-infestation (garlic and onion), after which they were again checked for the presence of mites. It was not possible to obtain quantitative data at that time due to very high population densities. Mites were again collected for genotyping.

\section{Experimental data analysis}

To quantify colonisation ability of the MT-1 lineage on different hosts a simple population growth model was applied:

$$
\ln \left(n_{t} / n_{0}\right) / t=r_{i}
$$

where $r_{i}$ is the effect for host plant $i$ (mean daily population growth rate), $n_{t}$ is population size at time $t$ and $n_{0}$ is the initial population size. This model implies that the number of individuals in the population changes as a fraction of $n_{0}$ at a constant rate, which varies only across different host plants. To estimate $r$ for each trial (in both transfer and colonisation experiments) we fitted a linear model to log-transformed counts made at two different time points. The slope parameter $r$ from these fitted models is a measure of mean daily population growth rate. In the case of the transfer experiments, $n_{0}$ was the exact count of females which successfully settled (i.e. females transferred minus dead or injured), and $n_{t}$ was the number of all specimens found after 28 days. A complete life cycle of WCM takes 8-10 days under favourable conditions, and at most 13 days at $20^{\circ} \mathrm{C}$ (Navia et al., 2013). Thus, after 28 days a third generation of mites in the experimental population would be expected in the case of successful colonisation. In the colonisation test, population counts were made after 14 and 29 days. As the leaves used for these experiments were clean, the initial number of individual mites on test plants at the beginning of each experiment was zero. To account for this, the linear model used to estimate $r$ was fit without an intercept in colonisation experiments.

To test if $r$ differed significantly between test plants, a simple ANOVA was performed. Pairs of mean population growth rates were compared using least significant difference (LSD) values at the 0.05 level of significance. Ninety-five percent confidence intervals around means of $r$ (CI hereafter) were calculated using bias corrected and accelerated bootstrap (Efron \& Tibshirani, 1993). For computations, R 3.0.2 was used (R Development Core Team, 2013).

\section{Molecular analyses}

\section{Specimens collection}

Field-sampled WCM populations were collected from the following plant species and countries: bread wheat, triticale, maize and smooth brome were sampled in Poland, bread wheat and wall barley in Turkey, and bread wheat in USA [Nebraska (NE) and Texas (TX)] (Table 1). Specimens from Poland and Turkey were collected in 2009-2012 into Eppendorf tubes containing $180 \mu \mathrm{L}$ of ATL buffer (Qiagen $\mathrm{GmbH}$ ) for DNA extraction while US specimens were collected in 1998 as described by Harvey et al. (1999). Wheat curl mite populations from USA were maintained as established colonies and stored as previously described (Hein et al., 2012). The morphological identification of WCM was confirmed by examining slide-mounted specimens from each extracted sample with a phase-contrast microscope.

DNA extraction, amplification and sequencing. For specimens from Poland and Turkey stored in ATL buffer, a nondestructive method of DNA isolation, as described by Dabert et al. (2008), was performed. The number of specimens used for each DNA extraction varied from one to several. The cytochrome $c$ oxidase subunit I (COI) gene fragment was amplified by PCR with the degenerate primers bcdF01 and bcdR04 (Skoracka $\delta$ Dabert, 2010). The PCR was carried out in $10 \mu \mathrm{L}$ reaction volumes containing $5 \mu \mathrm{L}$ Type-it Multiplex PCR Master Mix (Qiagen $\mathrm{GmbH}$ ), $0.5 \mu \mathrm{L}$ of each primer and $4 \mu \mathrm{L}$ of DNA template. A thermocycle profile of one cycle of $5 \mathrm{~min}$ at $95^{\circ} \mathrm{C}$ followed by 35 steps of $30 \mathrm{~s}$ at $95^{\circ} \mathrm{C}, 30 \mathrm{~s}$ at $50^{\circ} \mathrm{C}$, and $1 \mathrm{~min}$ at $72^{\circ} \mathrm{C}$, with a final step of $15 \mathrm{~min}$ at $72^{\circ} \mathrm{C}$ was applied. The ribosomal DNA (rDNA) fragment containing complete ITS1, 5.8S and partial ITS2 regions was amplified with the primers f1 230 (Skoracka \& Dabert, 2010) and 28Srev430 (CAACTTTCCCTCACGGTACTTGT$\left.3^{\prime}\right)$. The PCR followed a similar procedure as for COI, except that primers were diluted twofold and the elongation time of PCR was 2 min instead of 1 min. The PCR products were diluted with $10 \mu \mathrm{L}$ of water and $3 \mu \mathrm{L}$ of the product was analysed by electrophoresis in a $1 \%$ agarose gel. Samples containing visible, single bands were directly sequenced in both directions using $0.5-1 \mu \mathrm{L}$ of the PCR product and $50 \mathrm{pmol}$ of the corresponding sequencing primer, that is bcdF01 and bcdR04 for COI, and ITS1-18S (Navajas et al., 1999) and 28Srev430 for ITS 1, 5.8S and ITS2. Sequencing was performed with 
BigDye Terminator v3.1 on an ABI Prism 3130XL or 3730 Analyzer (Applied Biosystems, Foster City, CA, USA). Trace files were checked and edited using MEGA5 (Tamura et al., 2011).

For the USA-NE and USA-TX WCM populations, 1-5 mites were collected from infested plants or preserved samples and placed in $0.5 \mathrm{~mL}$ PCR reaction tubes in $20 \mu \mathrm{L} 1 \times$ PCR buffer (Roche, Indianapolis, IN, USA) and stored at $-20^{\circ} \mathrm{C}$ until PCR assays were performed. Prior to PCR, mite-containing tubes were heated to $99^{\circ} \mathrm{C}$ for $5 \mathrm{~min}$ and then placed on ice. PCR primers 16SF (5'-AATCAAAAGTCTATTAATTGTAGACCTG-3') and COIR (5'-ATAGAAATAGTAGCTAATCAACTAA-3') at $0.5 \mu \mathrm{M}$ final concentration, deoxynucleotide triphosphates (dNTPs) (final concentration of each $0.2 \mathrm{mM}$ ), $4 \mu \mathrm{L} 10 \times$ PCR buffer, and 1.25 units Expand High Fidelity System (Roche) were added to each tube, in addition to sufficient sterile water to make a final volume of $50 \mu \mathrm{L}$. PCR amplification was carried out with 35 cycles of $94^{\circ} \mathrm{C}$ for $1 \mathrm{~min}, 52^{\circ} \mathrm{C}$ for one min, and $72^{\circ} \mathrm{C}$ for $4 \mathrm{~min}$. Following PCR amplification, the $\sim 2.5 \mathrm{~kb}$ DNA products were purified using High-Pure spin columns (Roche) and stored at $-20^{\circ} \mathrm{C}$ before ligation into T-tailed pGEM-T Easy (Promega, Madison, WI, USA) and transformed into E. coli JM109. Nucleotide sequences of both strands were obtained by automated sequencing (Davis Sequencing, Inc., Davis, CA, USA) by primer walking using a minimum of three independent clones per sequence. Automated sequence data were compiled using Sequencher 4.1 (Gene Codes, Ann Arbor, MI, USA). All sequences have been deposited in GenBank under the accession numbers listed in Table 1.

Sequences from GenBank. To assess the global distribution of WCM lineages, additional sequences were obtained from WCM populations collected on bread wheat in Australia and South America, wall barley in Australia and rescuegrass in Australia; all deposited in GenBank by Skoracka et al. (2012). Sequences of the MT-7 lineage from Poland that was specific to wild and cultivated barley (Hordeum spp.) were also included in the phylogenetic analysis, in addition to the MT-1 lineage collected from quackgrass, smooth brome and tall oat-grass (Skoracka et al., 2013). Additional analyses were performed on sequences of a nuclear internal transcribed spacer region (ITS1) obtained from WCM populations in Europe, Australia and North and South America deposited in GenBank by Skoracka et al. (2012), Carew et al. (2009) and Hein et al. (2012). Accession numbers for all analysed sequences are listed in Table 1. Aceria eximia Sukhareva from the wood small-reed, Calamagrostis epigejos (L.) Roth was chosen as an outgroup for molecular analyses (GenBank: EF409415 for COI and JF920113 for ITS1).
Sequence analyses. Cytochrome $c$ oxidase subunit I and nuclear rDNA sequences were aligned separately by CLUSTALW using MEGA 5 (Tamura et al., 2011) with default gap weighting parameters, followed by manual adjustment. Alignment of the COI sequences covering $603 \mathrm{bp}$ of the $5^{\prime}$ terminus of COI gene was checked by translating the aligned DNA into amino acids. We used two datasets of rDNA sequences. One alignment, containing ITS1 sequences from different continents (sourced from GenBank), was cut to a uniform length of $348 \mathrm{bp}$ since most of the available ITS 1 sequences were of this length. The second alignment contained additional sequences obtained under this study from the MT-1, MT7 and MT- 8 lineages. The rDNA forward and reverse sequences were aligned and assembled to form a $755 \mathrm{bp}$ sequence covering ITS 1, 5.8S and part of the ITS2 region. These longer sequences were used to compare the MT-1, MT-7 and MT- 8 lineages, as they were more informative than the shorter $(348 \mathrm{bp}$ ) sequences.

The best-fit models of nucleotide substitution were selected with jModeltest ver. 2.1.4. (Guindon \& Gascuel, 2003; Darriba et al., 2012) based on likelihood scores for 88 different models, Akaike Information Criterion (AIC) and Bayesian Information Criterion (BIC). The TPM3uf + I model (Kimura, 1981; Posada, 2008) was chosen as the best model for the maximum likelihood (ML) analysis for COI sequences according to AIC. Estimated base frequencies were: $\mathrm{A}=0.22, \mathrm{C}=0.17$, $\mathrm{G}=0.15$, and $\mathrm{T}=0.46$ and the proportion of invariable sites was $(p$-inv $)=0.6700$. The $\mathrm{HKY}+\mathrm{I}$ substitution model (Hasegawa et al., 1985) was chosen for the Bayesian inference (BI) of phylogeny for COI sequences according to BIC, with the same estimated base frequencies as above. The transition/transversion ratio was $(\mathrm{ti} / \mathrm{tv})=6.8831$ and the proportion of invariable sites was $(p-i n v)=0.6760$. For the nuclear rDNA datasets, the TPM2 substitution model (Kimura, 1981; Posada, 2008) was chosen for ML with equal base frequencies and the K80 model (Kimura, 1980) was chosen for BI.

Pairwise distances between nucleotide sequences were calculated using PAUP* 4.0b10 (Swofford, 2003) with graphical frontend PaupUp v.1.0.3.1 for Windows (Calendini \& Martin, 2005). The Kimura 3-parameter model (Kimura, 1981) [K81, modified to TPM3 by Posada (2008)] with proportion of invariable sites was applied for the COI dataset and the general time-reversible (GTR) model set with jModeltest generated PAUP* block was applied for the ITS1, 5.8S and ITS2 dataset, according to prior jModeltest estimates. The mean within- and among-lineage distances with standard error estimates obtained using a bootstrap procedure (1000 replicates) were calculated in R 3.0.2 (R Development Core Team, 2013). 
Since in many studies the genetic distances are not calculated with models chosen for specific data [recently criticised by Srivathsan \& Meier (2012)], the uncorrected $p$-distances with standard error estimates (obtained with a bootstrap procedure; 1000 replicates) were also calculated using MEGA5 (Tamura et al., 2011). This simple distance measure was implemented to optimise estimates of both intra- and inter-lineage genetic variation, as in other studies of invertebrate diversity (e.g. Lim et al., 2012; Hsu et al., 2013; Schwentner et al., 2013).

Additional analysis of COI sequences was carried out in order to construct the BI tree presenting the lineages discussed in this study in relation to all WCM lineages detected thus far (Skoracka et al., 2013). For this analysis the HKY $+\mathrm{G}$ model was chosen by jModeltest. Estimated base frequencies were: $\mathrm{A}=0.24, \mathrm{C}=0.14, \mathrm{G}=0.13$, and $\mathrm{T}=0.49$, the gamma shape parameter was $(\mathrm{G})=0.1730$, and the transition/transversion ratio was $(\mathrm{ti} / \mathrm{tv})=7.1572$.

Maximum likelihood analyses were performed with PhyML 3.0 (Guindon et al., 2010). Analyses were set to optimise branch lengths and the tree topology search method used a nearest neighbour interchange algorithm. For each ML analysis, the approximate likelihoodratio test (aLRT) (Anisimova \& Gascuel, 2006) was performed. Bayesian inference approach estimation of phylogenetic relationships was performed with MrBayes v.3.2 (Ronquist et al., 2012). For each dataset, two independent runs were performed and each consisted of four chains with number of generations developed until the average standard deviation of split frequencies was less than 0.01 . A $50 \%$ majority consensus tree with posterior probability values was composed out of obtained trees, with exclusion of $25 \%$ of trees produced at the beginning of the analyses.

\section{Results}

\section{Host colonisation ability of the MT-1 lineage}

The colonisation tests showed that mites belonging to the MT-1 lineage (confirmed by COI sequence, sequences identical to JF920077) can successfully colonise wheat $(r=0.28 ;$ CI: $0.27-0.28)$, triticale $(r=0.29$; CI: $0.28-0.30)$, and maize $(r=0.19 ; \quad$ CI: $0.18-0.19)$ by moving from adjacent, infested wheat plants, although the population growth rate was significantly lower on maize compared to the other two cereal species (Fig. 1). The results of the 28-day observations of MT-1 mites showed that colonisation of garlic $(r=0.12$; CI: $0.10-0.13)$, onion $(r=0.10$; CI: $0.10-0.11)$ and tulip $(r=0.11$; CI: $0.10-0.11)$ was successful, although the population growth rate was significantly lower on Amaryllidaceae and Liliaceae compared to wheat (Fig. 2). Genotyping confirmed that the MT-1 lineage colonisation of

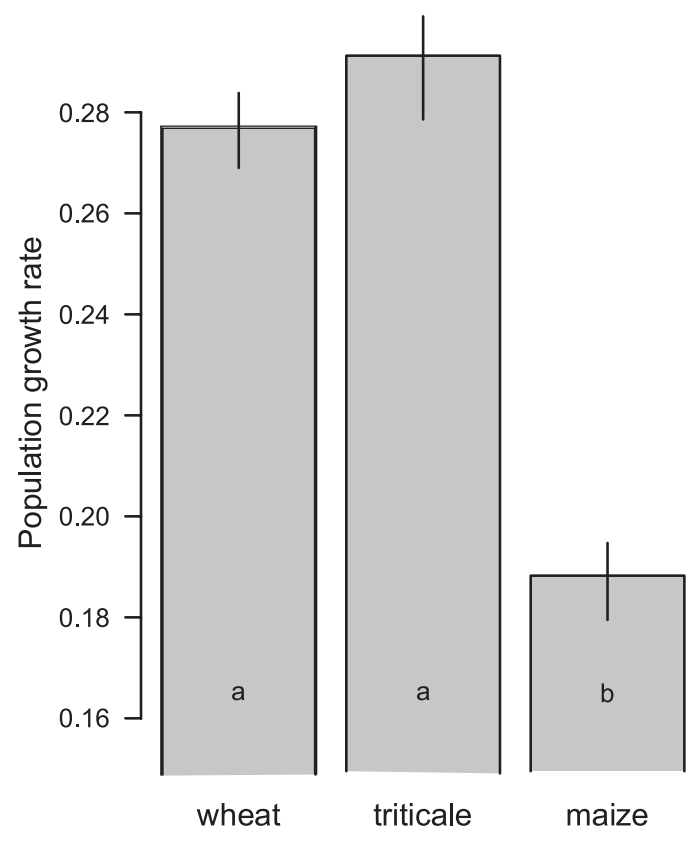

Figure 1 Population growth rates $(r)$ of the wheat curl mite MT-1 lineage engaged in host colonisation tests. Bootstrapped $95 \%$ confidence intervals around means of $r$ are shown. Treatments with the same letter were not significantly different (least significant difference test).

tulip was still active after 3 months and garlic and onion after 5 months, reaching very high population densities (data not shown).

\section{Phylogenetic analyses}

The COI dataset consisted of 21 aligned sequences of $603 \mathrm{bps}$ representing 11 unique haplotypes (unique sequences) of WCM (i.e. Aceria tosichella sensu lato) and one outgroup species. No insertions or deletions were found. Within the alignment, 156 positions were variable. The Kimura 3-parameter plus invariable sites COI genetic distance among all sequences (including outgroup) ranged from $0 \%$ to $32.3 \%$, and averaged $17.2 \%(\mathrm{SE}=0.8 \%)$, whereas distances among WCM sequences ranged from $0 \%$ to $28.1 \%$ and averaged $15.8 \%(\mathrm{SE}=0.8 \%)$. The uncorrected $p$-distance among all sequences (including outgroup) ranged from $0 \%$ to $19.4 \%$, and averaged $11.2 \%(\mathrm{SE}=1.0 \%)$, whereas among WCM sequences it ranged from $0 \%$ to $17.1 \%$ and averaged $10.4 \% \quad(\mathrm{SE}=1.0 \%)$. Structures of the phylogenetic trees inferred by BI and ML consistently showed the same topology (Fig. 3). Wheat curl mite sequences clustered into three distinct and well supported lineages ( $\geq 0.98$ for $\mathrm{BI}$ and 81 for ML). Two of the lineages comprised COI genotypes that were previously designated MT-1 and MT-7. The third 


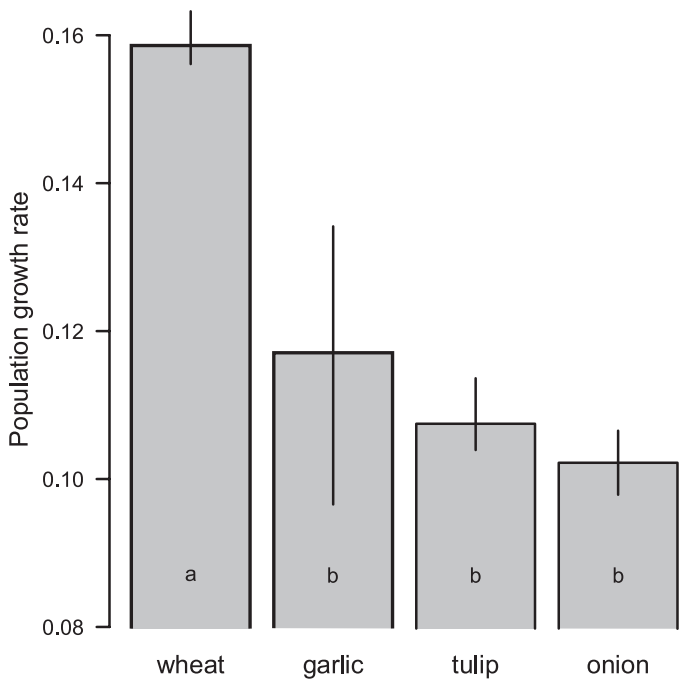

Figure 2 Population growth rates ( $r$ ) of the wheat curl mite MT-1 lineage when transferred to Amaryllidaceae and Liliaceae plants. Bootstrapped 95\% confidence intervals around means of $r$ are shown. Treatments with the same letter were not significantly different (least significant difference test).

lineage is designated here as MT-8 (Fig. 3). The intralineage Kimura 3-parameter and $p$-distance divergences were both $<1 \%(0.3-0.7 \%)$, whereas the inter-lineage Kimura 3-parameter divergence was $>17 \%$ and ranged from $17.5 \%$ to $26.2 \%$, and the inter-lineage $p$-distance divergence was $>11 \%$, ranging from $11.3 \%$ to $14.4 \%$. Pairwise comparisons of the COI distances within and between WCM lineages and between lineages and outgroup species are presented in Table 2. The MT1 populations analysed here were collected from five different plant species, viz. wheat and four wild grasses, and MT-1 was found on wheat on all five continents surveyed, viz. North and South America, Europe, Asia, Australia (Fig. 3). The MT-7 lineage included populations infesting wheat and wall barley and was found in Europe, Asia and Australia (Fig. 3). The MT-8 lineage was collected from three cereal species and one forage grass species and was found in North America, Europe, Asia, Australia (Fig. 3). The three invasive lineages were shown to be genetically distinct from the other European lineages described thus far (Fig. 5) in addition to having been recorded from multiple hosts, including domesticated cereals, unlike the other known European lineages (Skoracka et al., 2013).

The complete ITS 1 dataset consisted of 19 aligned sequences of $348 \mathrm{bps}$ representing 18 sequences of WCM and one outgroup sequence. Within the alignment, 31 positions were variable. The uncorrected $p$-distance (including the outgroup taxon) ranged from $0 \%$ to $8.6 \%$ and averaged $1.4 \%(\mathrm{SE}=0.3 \%)$. The mean uncorrected
Table 2 Percentage average Kimura 3-parameter with invariable site distances (upper) and uncorrected p-distances (lower) (with standard error estimates in parentheses) for mtDNA COI gene sequences within WCM lineages (bold) and between WCM lineages and outgroup species ${ }^{a}$

\begin{tabular}{llll}
\hline & MT-1 & MT-7 & MT-8 \\
\hline MT-1 & $\mathbf{0 . 7}(\mathbf{0 . 1})$ & & \\
& $\mathbf{0 . 7 ( 0 . 2 )}$ & & \\
MT-7 & $23.1(0.1)$ & $\mathbf{0 . 3 ( 0 . 2 )}$ & \\
& $13.8(1.3)$ & $\mathbf{0 . 3 ( 0 . 1 )}$ & \\
MT-8 & $26.2(0.1)$ & $17.5(0.1)$ & $\mathbf{0 . 3 ( 0 . 1 )}$ \\
& $14.4(1.4)$ & $11.3(1.2)$ & $\mathbf{0 . 3 ( 0 . 1 )}$ \\
Aceria eximia & $28.2(0.2)$ & $31.2(0.4)$ & $31.4(0.2)$ \\
& $15.6(1.5)$ & $16.8(1.4)$ & $16.7(1.5)$ \\
\hline
\end{tabular}

COI, cytochrome c oxidase subunit I; mtDNA, mitochondrial DNA; WCM, wheat curl mite.

a For a definition of each lineage, see Figs 3-5.

Table 3 Percentage average GTR distances (upper) and uncorrected $p$ distances (lower) (with standard error estimates in parentheses) for the long data set (758 bp) comprising ITS1, 5.8S and ITS2 gene sequences within WCM lineages (bolded) and between WCM lineages and outgroup species $^{\mathrm{a}}$

\begin{tabular}{llll}
\hline & MT-1 & MT-7 & MT-8 \\
\hline MT-1 & $\mathbf{0 . 0 ( 0 . 0 )}$ & & \\
MT-7 & $\mathbf{0 . 0 ( 0 . 0 )}$ & & \\
& $2.2(0.02)$ & $\mathbf{0 . 1 ( 0 . 0 3 )}$ & \\
MT-8 & $2.2(0.5)$ & $\mathbf{0 . 1 ( 0 . 1 )}$ & \\
& $2.6(0.0)$ & $0.4(0.02)$ & $\mathbf{0 . 0 ( 0 . 0 )}$ \\
Aceria eximia & $2.5(0.6)$ & $0.4(0.2)$ & $\mathbf{0 . 0 ( 0 . 0 )}$ \\
& $7.2(0.0)$ & $6.2(0.0)$ & $6.7(0.0)$ \\
& $6.9(0.9)$ & $6.0(0.8)$ & $6.4(0.9)$ \\
\hline
\end{tabular}

GTR, general time reversible (model); ITS1, internal transcribed spacer region; WCM, wheat curl mite.

${ }^{a}$ For a definition of each lineage, see Figs 3-5.

$p$-distance among WCM sequences was $0.6 \%(\mathrm{SE}=0.3 \%)$ and ranged from $0 \%$ to $1.4 \%$. This short ITS 1 dataset was not very informative compared to the longer rDNA dataset that included ITS 1 as well as sequences from the adjacent $5.8 \mathrm{~S}$ and ITS2 regions. The longer dataset consisted of 10 aligned sequences of $758 \mathrm{bps}$ representing nine sequences of WCM and one outgroup sequence. Within this alignment, 59 positions were variable. The mean uncorrected $p$-distance over all sequences (including the outgroup taxon) was $2.3 \%(\mathrm{SE}=0.3 \%)$ and ranged from $0 \%$ to $6.9 \%$, whereas GTR distance ranged from $0 \%$ to $7.3 \%$, and averaged $2.4 \% \quad(\mathrm{SE}=0.3 \%)$. The mean $p$-distance among WCM sequences was $1.3 \%$ ( $\mathrm{SE}=0.3 \%$ ) and ranged from $0 \%$ to $2.5 \%$, whereas GTR distance ranged from $0 \%$ to $2.6 \%$ and averaged $1.3 \%$ $(\mathrm{SE}=0.2 \%)$. Pairwise comparisons of the ITS distances within and between WCM lineages and between lineages and outgroup species are presented in Table 3. 


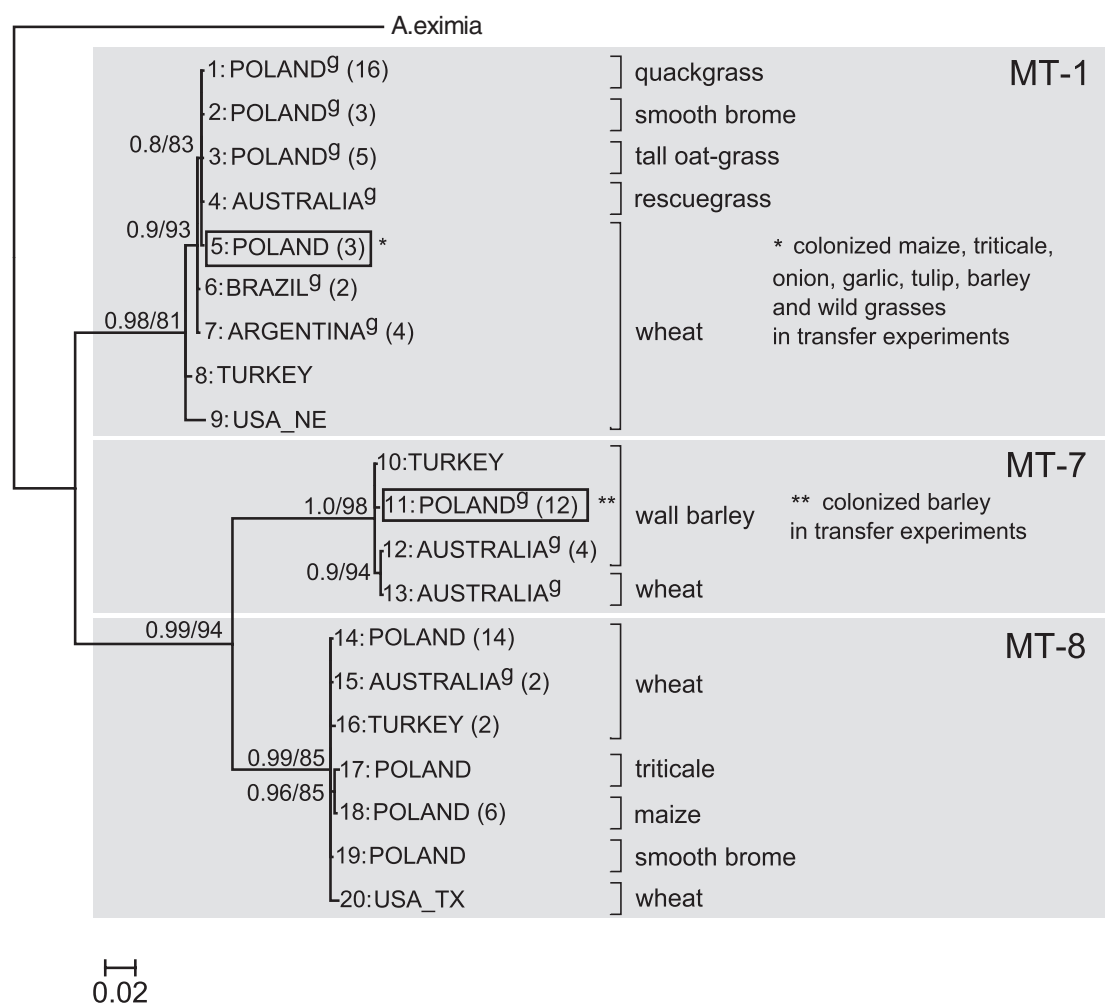

Figure 3 Bayesian inference (BI) tree constructed using the HKY + I model for the cytochrome c oxidase subunit 1 (COI) sequences of the wheat curl mite and outgroup species, Aceria eximia, showing the host plants and distribution of three wheat curl mite (WCM) lineages. For genotypes in frames host colonisation ability was experimentally tested. Numbers in parenthesis refer to numbers of independent records of a given genotype. Populations of WCM are numbered and numbers correspond to data in Table 1. A concordant tree was obtained by maximum likelihood (ML) analysis, that produced the same topology in defining groups. Statistical supports indicate Bayesian posterior probabilities/ML aLRT values. Only statistical supports higher than $0.6 / 60$ are indicated above branches. Sequences designated with $(g)$ in superscript were obtained from GenBank under accession numbers listed in Table 1.

Analysis of the short (348 bp) dataset showed marked polytomy with a subclade representing MT-1, whereas analysis of the larger dataset $(758 \mathrm{bp}$, including ITS 1, 5.8S and ITS2) revealed divergence between the MT-1 lineage and the MT-7 and MT-8 lineages, with MT- 8 appearing as a subclade within MT-7 (Fig. 4). While the divergence shown by the nuclear sequence data is not as distinct as in the case of the COI data, the nuclear data ultimately support the COI data (Figs 3 and 4).

\section{Discussion}

In this study, phylogenetic analyses of mitochondrial and nuclear DNA sequence data from WCM populations collected from both wild and cultivated grass species in six countries on five continents revealed that the invasive WCM populations in North and South America and Australia assorted with two of the seven lineages previously described by Skoracka et al. (2013), MT-1 and MT-7, in addition to a previously undescribed lineage, designated MT-8 (see Fig. 5). The genetic divergence between mitochondrial lineages studied here was high, taking into account both average mean divergence over all sequences and the distance between specific lineages (Table 2) indicating that the lineages may be considered as different operational taxonomic units (OTUs). These three invasive lineages represent the only pestiferous WCM lineages yet described, based on bioassay data measuring the host-acceptance and population growth of each lineage on a variety of wild and cultivated putative host plant species. None of the other five known lineages (viz. MT-2 through MT-6), each of which appears to specialise on one of a few wild grass species (see Skoracka et al., 2013), has been recorded outside of Europe. The extent of geographic movement of the crop and cereal-associated WCM lineages underlines the need for additional surveys on invaded continents for other WCM lineages, that is those not associated with agricultural plants, that may be affecting natural ecosystems. Such surveys would logically cover native congeners of the known hosts of 


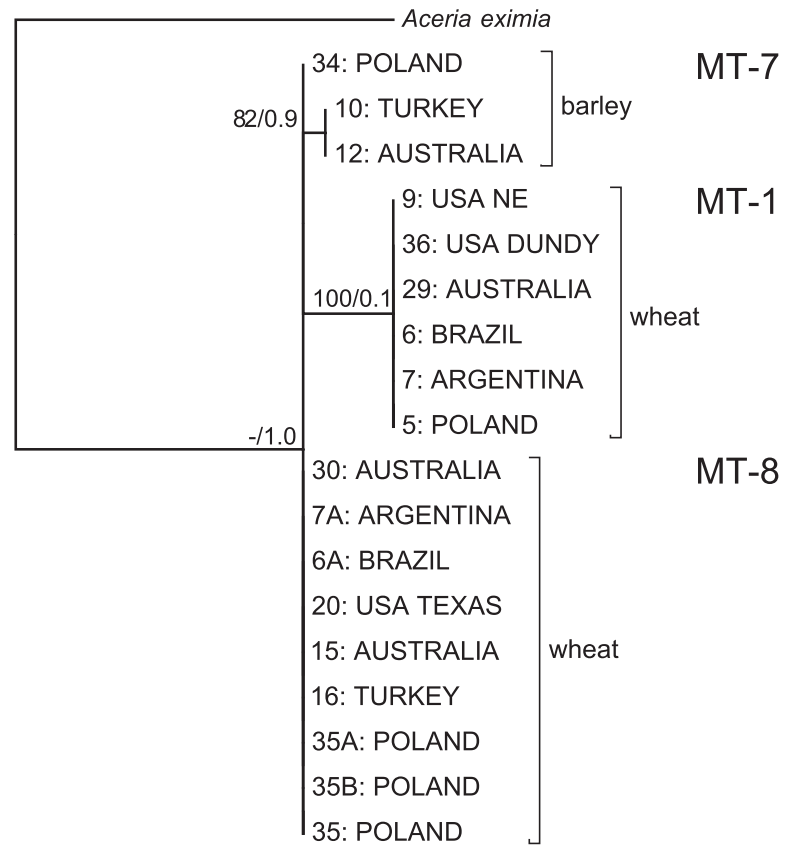

$\stackrel{\stackrel{H}{H}}{0.002}$

A

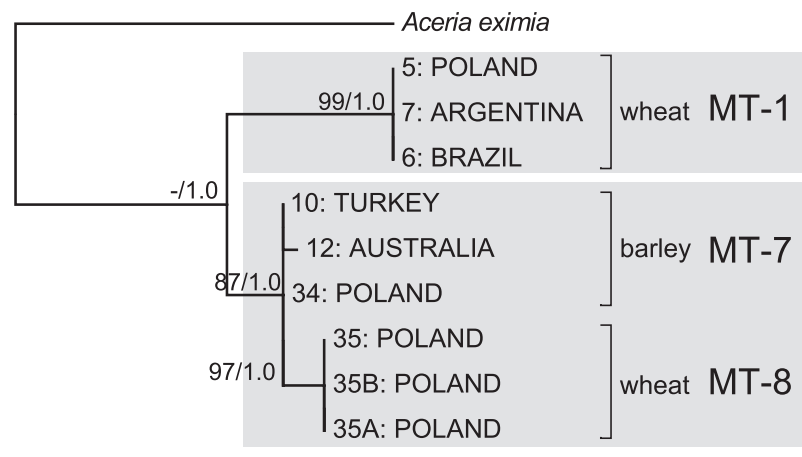

$\stackrel{\mapsto}{0.002}$

B

Figure 4 Maximum likelihood tree constructed using the TPM2 model for the ITS1 dataset (A) and ITS1, 5.8S and ITS2 dataset (B) of sequences from wheat curl mite populations in Europe, Australia, North America and South America. A concordant tree was obtained by Bayesian inference (BI), that produced the same topology. Statistical supports indicate ML/aLRT values/Bayesian posterior probabilities. Only statistical supports higher than $60 / 0.6$ are indicated above branches. Populations of wheat curl mite (WCM) are numbered and numbers correspond to data in Table 1.

described WCM lineages (e.g. Bromus spp., Elymus spp.) in regions invaded by pestiferous WCM lineages.

The MT-1 lineage, which diverged by $>13 \%$ (uncorrected $\mathrm{p}$-distance) and $>23 \%$ (K81 distance) in COI sequence from the two other invasive lineages, was shown here to be capable of colonising maize (Fig. 1) and bulbs of garlic, onion and tulip (Fig. 2) although on these hosts its population growth was significantly slower than on wheat, the presumed preferred host. MT1 colonised maize in this study after a wheat plant densely populated with mites was placed in contact with a clean maize plant, whereas in a previous study (Skoracka et al., 2013) manual transfer of 15 mites from wheat to maize did not enable successful colonisation. MT-1 has now been shown to successfully colonise all 10 plant species (in three families) offered as hosts in bioassays and has spread to all five continents (viz. North and South America, Europe, Asia, Australia) surveyed in this study. The other invasive lineages identified here, viz. MT-7 and MT-8, were each present on several continents but were not recorded on or were not able to colonise plants outside the family Poaceae (Skoracka et al., 2013). These latter two lineages are also more closely related to each other than to MT- 1 based on DNA sequence data (Figs 3-5, and Tables 2 and 3). It is possible that MT-7 and MT-8 lineages may hybridise when encountering each other on wheat, although wheat may be an accidental host for MT-7 (see below). This assumption can be supported by the similarity of the nuclear ITS gene data (Fig. 4). Further sampling of these lineages throughout their ranges, as well as analyses of additional DNA markers (e.g. SSR or SNP) will be necessary to detect potential hybridisation among multiple WCM lineages.

MT-7 and MT-8 were recorded from three (Europe, Asia, Australia) and four (North America, Europe, Asia, Australia) continents, respectively. MT-7 was collected from wall barley in Poland, Turkey and Australia (Fig. 3) and colonised common barley in host-range testing of the Polish population (Skoracka et al., 2013). However, the same host-range tests indicated that MT-7 could not colonise wheat. Thus it is possible that the record of MT-7 on wheat in Australia was accidental. Additional hostrange tests on all MT-7 populations will be necessary to determine whether this lineage is restricted to Hordeum spp. hosts. MT- 8 was collected from three distantly related Poaceae genera (viz. Bromus L., Triticum L., and Zea L.) but its host range has yet to be assessed experimentally.

All three pestiferous, invasive WCM lineages were represented in both Europe (Poland) and southwest Asia (Turkey), supporting the assumption made at the outset of this study that $A$. tosichella originated in Europe or adjacent areas of Asia and was spread globally from there, mainly through its association with cultivated cereal species. It is logical to further hypothesise that the modern (i.e. post-Columbian) invasion of the Americas and Australia by WCM mirrors a previous spread throughout prehistoric grain-producing regions of Eurasia and Africa although additional collections and phylogenetic analyses with additional genetic markers will be necessary to test this hypothesis. It may also be postulated, based on the presence of several lineages of $A$. tosichella sensu lato that 


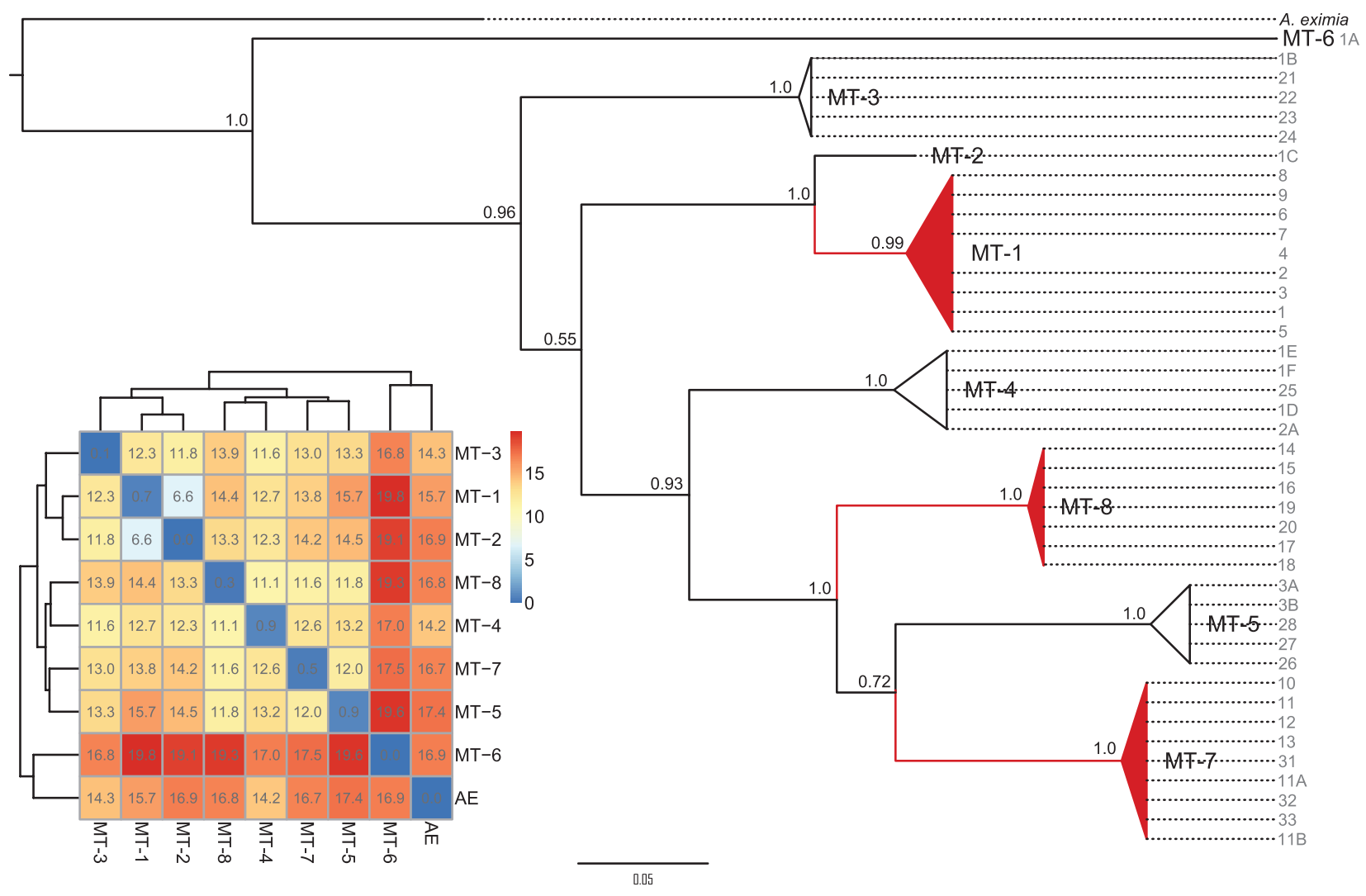

Figure 5 Bayesian inference (BI) tree constructed using the HKY $+\mathrm{G}$ model for the cytochrome $c$ oxidase subunit 1 (COI) sequences of all currently known wheat curl mite (WCM) COI lineages and one outgroup species. Lineages from MT-1 to MT-7 have been distinguished in a previous study (Skoracka et al., 2013) on the basis on molecular and host-specificity data. Each WCM lineage is represented by all known specimens. The lineages discussed in this study (see Fig. 3) are marked with red triangles. The labels correspond to sequence labels provided in Table 1. Statistical supports above branches indicate Bayesian posterior probabilities. Heat map represents pairwise uncorrected $p$-distances for COI gene.

utilise various wild grasses but not wheat (Skoracka et al., 2013), that the progenitor of today's A. tosichella utilised one or more related grass species prior to the domestication of wheat and other cereals.

Speciation of WCM due to pre-zygotic reproductive barriers appears to be underway in the European range (Skoracka et al., 2013), including but not limited to separation by divergent host utilisation. Intercontinental invasion by a subset of WCM lineages is also likely to promote speciation of WCM due to geographic separation from non-invasive lineages remaining in Europe, as well as exposure of invasive populations to indigenous or other potential host species on invaded continents. Invasive, polyphagous WCM lineages could spread away from cereal-producing areas of their invaded ranges into areas dominated by such novel hosts and cause environmental concern in addition to economic damage (Marini et al., 2011). The record of MT-1 in Australia on rescuegrass (Bromus catharticus Vahl), an introduced forage species from South America (Wu et al., 2009), is an illustration of this possibility. In addition to its broader host range on grasses, the ability of MT-1 mites to survive on bulbs of species such as garlic, onion, and tulip increases the potential for MT-1 movement between and within continents in comparison to the other, grass-specific WCM lineages whose survival off of green plants is very limited (G. Hein, unpublished data). This enhanced dispersal ability will likely lead to geographic isolation of some invasive MT-1 populations, away from other WCM lineages, and expose them to unique selection pressures.

All three invasive WCM lineages have been recorded in Australia and two of these three lineages have been recorded in North America, highlighting the global scale of this invasion. As with other mites, prevention of these invasions is hindered by the mite's minute size and the ability of a single female to found a colony (Boubou et al., 2010; Michalska et al., 2010). The detection here of three different invasive WCM lineages in Australia, combined with earlier findings showing that WCM populations in Australia differed in their ability to transmit WSMV 
(Carew et al., 2009), also underscores the need for separate testing of the ability of different WCM lineages on all continents to transmit WSMV and other plant viruses.

\section{Acknowledgements}

We thank Zofia Banaszak (director of plant breeding centre DANKO) for permission to collect wheat, Mirosława Dabert (Molecular Biology Techniques Laboratory, Faculty of Biology, Adam Mickiewicz University [AMU]) for designing the primer 28Srev430, Urszula Sobczyńska (AMU, Poland) for help with laboratory work, Evsel Denizhan for providing three samples, the editor of Annals of Applied Biology and two anonymous reviewers for helpful comments that greatly improved the manuscript. The study was funded by the National Science Centre in Poland (Grants Nos. 2011/03/B/NZ8/00129 and $2011 / 01 / \mathrm{N} / \mathrm{NZ} 8 / 04540)$. The US portion of this project was partially funded by USDA NC-IPM (CSREES) Grant No. 2004-34103-14443 and by USDA-ARS Specific Cooperative Agreement no. 58-5440-7-334. A.S. and L. K. conceived and designed the study. A.S. performed the experiments. A.S., W.S., G.H. and R.F. carried out the molecular genetic studies. L. K., A. S. and W.S. analysed the data. B. R. and A. S. wrote the manuscript. L. K., W. S., G.H. and R.F. partially wrote methods and results. All authors critically revised the manuscript and read and approved the final manuscript.

\section{References}

Anisimova M., Gascuel O. (2006) Approximate likelihoodratio test for branches: a fast, accurate, and powerful alternative. Systematic Biology, 55, 539-552.

Benheim D., Rochfort S., Robertson E., Potter I.D., Powell K.S. (2012) Grape phylloxera (Daktulosphaira vitifoliae) - a review of potential detection and alternative management options. Annals of Applied Biology, 161, 91-115.

Boubou A., Migeon A., Roderick G.K., Navajas M. (2010) Recent emergence and worldwide spread of the red tomato spider mite, Tetranychus evansi: genetic variation and multiple cryptic invasions. Biological Invasions, 13, $81-92$.

Byamukama E., Seifers D.L., Hein G.L., De Wolf E., Tisserat N.A., Langham M.A.C., Osborne L.E., Timmerman A., Wegulo S.N. (2013) Occurrence and distribution of Triticum mosaic virus in the Central Great Plains. Plant Disease, 97, 21-29.

Calendini F., Martin J.-F. (2005) PaupUP vl.0.3.1. A free graphical frontend for Paup* Dos software. http://www.agro-montpellier.fr/sppe/Recherche/JFM/ PaupUp/main.htm [accessed 25 April 2014].
Carew M., Schiffer M., Umina P., Weeks A., Hoffmann A. (2009) Molecular markers indicate that the wheat curl mite, Aceria tosichella Keifer, may represent a species complex in Australia. Bulletin of Entomological Research, 99, 479-486.

Dabert J., Ehrnsberger R., Dabert M. (2008) Glaucalges tytonis sp. n. (Analgoidea, Xolalgidae) from the barn owl Tyto alba (Strigiformes, Tytonidae): compiling morphology with DNA barcode data for taxon descriptions in mites (Acari). Zootaxa, 1719, 41-52.

Darriba D., Taboada G.L., Doallo R., Posada D. (2012) jModelTest 2: more models, new heuristics and parallel computing. Nature Methods, 9, 772.

Duso C., Castagnoli M., Simoni S., Angeli G. (2010) The impact of eriophyoids on crops: recent issues on Aculus schlechtendali, Calepitrimerus vitis and Aculops lycopersici. Experimental and Applied Acarology, 51, 151-168.

Efron B., Tibshirani R.J. (1993) An Introduction to the Bootstrap. London, UK: Chapman and Hall/CRC.

Guindon S., Gascuel O. (2003) A simple, fast, and accurate algorithm to estimate large phylogenies by maximum likelihood. Systematic Biology, 52, 696-704.

Guindon S., Dufayard J.F., Lefort V., Anisimova M., Hordijk W., Gascuel O. (2010) New algorithms and methods to estimate maximum-likelihood phylogenies: assessing the performance of PhyML 3.0. Systematic Biology, 59, 307-321.

Harvey T.L., Seifers D.L., Martin T.J., Brown-Guedira G., Gill B.S. (1999) Survival of wheat curl mites on different sources of resistant wheat. Crop Science, 39, 1887-1889.

Harvey T.L., Martin T.J., Seifers D.L. (2002) Wheat yield reduction due to wheat curl mite (Acari: Eriophyidae) infestations. Journal of Agricultural and Urban Entomology, 19, 9-13.

Hasegawa M., Kishino H., Yano T. (1985) Dating of the human-ape splitting by a molecular clock of mitochondrial DNA. Journal of Molecular Evolution, 22, 160-174.

Hein G.L., French R., Siriwetwiwat B., Amrine J.W. (2012) Genetic characterization of North American populations of the wheat curl mite and dry bulb mite. Journal of Economic Entomology, 105, 1801-1808.

Honek A., Martinkova Z. (2011) Body size and the colonisation of cereal crops by the invasive slug Arion lusitanicus. Annals of Applied Biology, 158, 79-86.

Hsu T.-H., Ning Y., Gwo J.-C., Zeng Z.-N. (2013) DNA barcoding reveals cryptic diversity in the peanut worm Sipunculus nudus. Molecular Ecology Resources, 13, 596-606.

Jeppson L.R., Keifer H.H., Baker E.W. (1975) Mites Injurious to Economic Plants. Los Angeles, CA, USA: University of California Press.

Juárez-Escario A., Valls J., Solé-Senan X.O., Conesa J.A. (2013) A plant-traits approach to assessing the success of alien weed species in irrigated Mediterranean orchards. Annals of Applied Biology, 162, 200-213.

Kimura M. (1980) A simple method for estimating evolutionary rate of base substitutions through comparative studies 
of nucleotide sequences. Journal of Molecular Evolution, 16, $111-120$.

Kimura M. (1981) Estimation of evolutionary distances between homologous nucleotide sequences. Proceedings of the National Academy of Sciences of the United States of America, 78, 454-458.

Lim P.-E., Tan J., Suana I.W., Eamsobhana P., Yong H.S. (2012) Distinct genetic lineages of Bactrocera caudata (Insecta: Tephritidae) revealed by COI and 16S DNA sequences. PLOS ONE, 7, e37276.

Lindquist E.E., Amrine J.W. (1996) Systematics, diagnoses for major taxa, and keys to families and genera with species on plants of economic importance. In Eriophyoid Mites - Their Biology, Natural Enemies and Control, pp. 33-87. Eds E.E. Lindquist, M.W. Sabelis and J. Bruin. Amsterdam, the Netherlands: Elsevier Science Publishers.

Magalhães S., Forbes M.R., Skoracka A., Osakabe M., Chevillon C., McCoy K.D. (2007) Host race formation in the Acari. Experimental and Applied Acarology, 42, 225-238.

Marini L., Haack R.A., Rabaglia R.J., Toffolo E.P., Battisti A., Faccoli M. (2011) Exploring associations between international trade and environmental factors with establishment patterns of exotic Scolytinae. Biological Invasions, 13, 2275-2288.

Mazzi D., Dorn S. (2012) Movement of insect pests in agricultural landscapes. Annals of Applied Biology, 160, 97-113.

Michalska K., Skoracka A., Navia D., Amrine J.W. (2010) Behavioural studies on eriophyoid mites: an overview. Experimental and Applied Acarology, 51, 31-59.

Miller A.D., Skoracka A., Navia D., de Mendonca R., Szydło W., Schultz M., Smith C.M., Truol G., Hoffmann A.A. (2013) Phylogenetic analyses reveal extensive cryptic speciation and host specialization in an economically important mite taxon. Molecular Phylogenetics and Evolution, 66, 928-940.

Navajas M., Lagnel J., Fauvel G., De Moraes G. (1999) Sequence variation of ribosomal Internal Transcribed Spacers (ITS) in commercially important Phytoseiidae mites. Experimental and Applied Acarology, 23, 851-859.

Navia D., Ochoa R., Welbourn C., Ferragut F. (2010) Adventive eriophyoid mites: a global review of their impact, pathways, prevention and challenges. Experimental and Applied Acarology, 51, 225-255.

Navia D., de Mendonça R.S., Skoracka A., Szydło W., Knihinicki D., Hein G.L., da Silva Pereira P.R.V., Truol G., Lau D. (2013) Wheat curl mite, Aceria tosichella, and transmitted viruses: an expanding pest complex affecting cereal crops. Experimental and Applied Acarology, 59, 95- 143.

Nosil P. (2007) Divergent host plant adaptation and reproductive isolation between ecotypes of Timema cristinae walking sticks. American Naturalist, 169, 151-162.

Oldfield G.N., Proeseler G. (1996) Eriophyoid mites as vectors of plant pathogens. In Eriophyoid Mites - Their Biology, Natural Enemies and Control, pp. 259-273. Eds E.E.
Lindquist, M.W. Sabelis and J. Bruin. Amsterdam, the Netherlands: Elsevier Science Publishers.

Pimentel D., Lach L., Zuniga R., Morrison D. (2000) Environmental and economic costs of nonindigenous species in the United States. Bioscience, 50, 53-65.

Posada D. (2008) jModelTest: phylogenetic model averaging. Molecular Biology and Evolution, 25, 1253-1256.

R Development Core Team (2013) R: A Language and Environment for Statistical Computing. $R$ Foundation for Statistical Computing. Vienna, Austria: R Foundation for Statistical Computing.

Ronquist F., Teslenko M., van der Mark P., Ayres D., Darling A., Höhna S., Larget B., Liu L., Suchard M.A., Huelsenbeck J.P. (2012) MrBayes 3.2: efficient Bayesian phylogenetic inference and model choice across a large model space. Systematic Biology, 61, 539-542.

Schiffer M., Umina P., Carew M., Hoffmann A., Rodoni B., Miller A. (2009) The distribution of wheat curl mite (Aceria tosichella) lineages in Australia and their potential to transmit wheat streak mosaic virus. Annals of Applied Biology, 155, 371-379.

Schluter D. (2001) Ecology and the origin of species. Trends in Ecology and Evolution, 16, 372-380.

Schwentner M., Clavier S., Fritsch M., Olesen J., Padhye S., Timms B.V., Richter S. (2013) Cyclestheria hislopi (Crustacea: Branchiopoda): a group of morphologically cryptic species with origins in the Cretaceous. Molecular Phylogenetics and Evolution, 66, 800-810.

Seifers D.L., Harvey T.L., Martin J., Jensen S.G. (1997) Identification of the wheat curl mite as the vector of the High Plains virus of corn and wheat. Plant Disease, 81, 1161-1166.

Seifers D.L., Martin T.J., Harvey T.L., Fellers J.P., Michaud J.P. (2009) Identification of the wheat curl mite as the vector of Triticum mosaic virus. Plant Disease, 93, 25-29.

Skoracka A., Dabert M. (2010) The cereal rust mite Abacarus hystrix (Acari: Eriophyoidea) is a complex of species: evidence from mitochondrial and nuclear DNA sequences. Bulletin of Entomological Research, 100, 263-272.

Skoracka A., Smith L., Oldfield G., Cristofaro M., Amrine J.W. (2010) Host-plant specificity and specialization in eriophyoid mites and their importance for the use of eriophyoid mites as biocontrol agents of weeds. Experimental and Applied Acarology, 51, 93-113.

Skoracka A., Kuczyński L., de Mendonça R.S., Dabert M., Szydło W., Knihinicki D., Truol G., Navia D. (2012) Cryptic species within the wheat curl mite Aceria tosichella (Keifer) (Acari, Eriophyoidea) revealed by mitochondrial, nuclear and morphometric data. Invertebrate Systematics, 26, 417-433.

Skoracka A., Kuczyński L., Szydło W., Rector B. (2013) The wheat curl mite Aceria tosichella (Acari: Eriophyoidea) is a complex of cryptic lineages with divergent host ranges: evidence from molecular and plant bioassay data. Biological Journal of the Linnean Society, 109, 165-180. 
Srivathsan A., Meier R. (2012) On the inappropriate use of Kimura-2-parameter (K2P) divergences in the DNAbarcoding literature. Cladistics, 28, 190-194.

Stephan D., Moeller I., Skoracka A., Ehrig F., Maiss E. (2008) Eriophyid mite transmission and host range of a Brome streak mosaic virus isolate derived from a full-length cDNA clone. Archives of Virology, 153, 181-185.

Styer W.E., Nault L.R. (1996) Corn and grain plants. In Eriophyoid Mites - Their Biology, Natural Enemies and Control, pp. 611-618. Eds E.E. Lindquist, M.W. Sabelis and J. Bruin. Amsterdam, the Netherlands: Elsevier Science Publishers.

Swofford D.L. (2003) PAUP*. Phylogenetic Analysis Using Parsimony (*and Other Methods). Version 4. Sunderland, MA, USA: Sinauer Associates.
Tamura K., Peterson D., Peterson N., Stecher G., Nei M., Kumar S. (2011) MEGA5: molecular evolutionary genetics analysis using maximum likelihood, evolutionary distance, and maximum parsimony methods. Molecular Biology and Evolution, 28, 2731-2739.

Wang X.G., Hogg B.N., Levy K., Daane K.M. (2013) Predicting the outcomes of a tri-trophic interaction between an indigenous parasitoid and an exotic herbivorous pest and its host plants. Annals of Applied Biology, 163, 288-297.

Wu S.H., Tsai J.K., Sun H.T., Chen C.F., Chiou C.R. (2009) Patterns of plant invasions in the preserves and recreation areas of Shei-Pa National Park in Taiwan. Botanical Studies, 50, 217-227. 